\title{
Complicações renais decorrentes da infecção por SARS-CoV-2 em pessoas com COVID-19 hospitalizadas: scoping review
}

\author{
Renal complications resulting from SARS-CoV-2 infection in hospitalized COVID-19 persons:
} scoping review

Complicaciones renales resultantes de la infección por SARS-CoV-2 en personas hospitalizadas por COVID-19: scoping review

\section{Resumo}

Objetivos: Identificar complicações/sequelas renais decorrentes da infecção por SARS-CoV-2 em pessoas com COVID-19; e descrever a característica de idade da população estudada. Metodologia: Scoping Review realizada nas bases de dados Web of Science, BVS, Cochrane Library, MEDLINE/PubMed, CINAHL, SCOPUS, Embase, LILACS. E nos sites online: ProQuest Dissertations and Theses, Grey Literature e Google Scholar. Os descritores utilizados foram (comorbidity OR sequel OR complications), (kidney diseases OR glomerular disease OR acute kidney injury OR nephropathy) AND (coronavirus OR SARS-CoV-2 OR COVID-19). Critérios de inclusão: artigos em português, inglês e espanhol, com abordagens metodológicas diversas, disponíveis na íntegra, online, publicados no período de 01 de janeiro de 2020 a 29 de setembro de 2021. E de exclusão: pessoas com diagnósticos prévios de patologias renais agudas e/ou crônicas; cartas ao editor; artigos de opinião; editoriais; e notas. Resultados: Selecionaram-se 10 artigos, que evidenciaram que o processo infeccioso causado pelo SARS-CoV-2 pode iniciar com uma leve proteinúria e hematúria, e evoluir para uma injúria renal aguda causada pela diminuição da capacidade de filtração glomerular, que favorece a retenção de algumas escórias nitrogenadas, causando o aumento dos níveis de creatinina e de ureia. Ademais, informaram que indivíduos entre 52-69 anos foram os mais acometidos. Considerações finais: As complicações/sequelas renais decorrentes da infecção por SARS-CoV-2 são: deposição de imunocomplexos nas células renais, proteinúria, hematúria, aumento da creatinina sérica, aumento da ureia nitrogenada no sangue, diminuição da TFG, e IRA estágio 1, 2 e 3. Tais complicações ocorreram principalmente em pessoas com idade $\geq 52$ anos.

Palavras-chave: SARS-CoV-2; COVID-19; Nefropatias; Injúria Renal Aguda.

\begin{abstract}
Aim: To identify renal complications/sequels resulting from SARS-CoV-2 infection in people with COVID-19; and to describe the age characteristic of the studied population. Methodology: Scoping Review performed in the databases Web of Science, BVS, Cochrane Library, MEDLINE via PubMed, CINAHL, SCOPUS, Embase, LILACS. And in online sites: ProQuest Dissertations and Theses, Gray Literature and Google Scholar. The descriptors used were (comorbidity OR sequel OR complications), (kidney diseases OR glomerular disease OR acute kidney injury OR nephropathy) AND (coronavirus OR SARS-CoV-2 OR COVID-19). Inclusion criteria: articles in portuguese, english
\end{abstract}


and spanish, with different methodological approaches, available in full, online, published from january 1,2020 to September 29, 2021. And exclusion: people with previous diagnoses of renal pathologies acute and/or chronic; letters to the editor; opinion articles; editorials; and notes. Results: Ten articles were selected, which showed that the infectious process caused by SARS-CoV-2 can start with mild proteinuria and hematuria, and progress to an acute kidney injury caused by the reduction in the glomerular filtration capacity, which favors the retention of some nitrogenous slag, causing increased creatinine and urea levels. Furthermore, they reported that individuals aged between 52-69 years were the most affected. Conclusions: Complications/sequels resulting from SARS-CoV-2 infection are: deposition of immune complexes in renal cells, proteinuria, hematuria, increase in serum creatinine, increase in nitrogenous urea in the blood, decrease in TGF, and AKI stage 1,2 and 3. These complications have mostly occurred in people aged $\geq 52$ years.

Keywords: SARS-CoV-2; COVID-19; Kidney diseases; Acute Kidney Injury.

\section{Resumen}

Objetivos: Identificar las complicaciones/secuelas renales resultantes de la infección por SARS-CoV-2 en personas con COVID-19; y describir la característica de edad de la población estudiada. Metodología: Scoping Review realizada en las bases de datos Web of Science, BVS, Cochrane Library, MEDLINE/PubMed, CINAHL, SCOPUS, Embase, LILACS. Y sites online: ProQuest Dissertations and Theses, Grey Literature y Google Scholar. Los descriptores utilizados (comorbidity OR sequel OR complications), (kidney diseases OR glomerular disease OR acute kidney injury OR nephropathy) AND (coronavirus OR SARS-CoV-2 OR COVID-19). Criterios de inclusión: artículos en portugués, inglés y español, con diferentes enfoques metodológicos, disponibles íntegramente, en línea, publicados desde el 1 de enero de 2020 al 29 de septiembre de 2021. Y exclusión: personas con diagnósticos previos de patologías renales agudas y/o crónicas; cartas al editor; artículos de opinión; editoriales; y notas. Resultados: Seleccionaron diez artículos, que mostraron que el proceso infeccioso causado por el SARS-CoV-2 puede comenzar con proteinuria leve y hematuria, progresar a una lesión renal aguda causada por la reducción de la capacidad de filtración glomerular, favoreciendo la retención de escorias de nitrógeno, aumentando los niveles de creatinina y urea. Además, las personas de 52-69 años fueron más afectadas. Clusiones: Las complicaciones/secuelas renales resultantes de la infección por SARS-CoV-2 son: depósito de complejos inmunes en las células renales, proteinuria, hematuria, aumento de la creatinina sérica, aumento de la urea nitrogenada en la sangre, disminución de la TFG e IRA en estadios 1, 2 y 3 . Estas complicaciones se presentaron principalmente en personas $\geq 52$ años.

Palabras clave: SARS-CoV-2; COVID-19; Enfermedades renales; Lesión Renal Aguda.

\section{Introdução}

A COVID-19 (Doença do Coronavírus 2019) é uma patologia infecciosa causada pelo vírus SARS-CoV-2 (Coronavírus relacionado à síndrome respiratória aguda grave 2) (World Health Organization, 2021a), sendo relatada pela primeira vez em dezembro de 2019 em Wuhan, na China. Devido à rápida disseminação da doença pelo mundo, a Organização Mundial de Saúde (OMS) caracterizou, em março de 2020, a COVID-19 como uma nova pandemia (Organização PanAmericana de Saúde, 2020). Atualmente, o mundo ainda se encontra em estado de pandemia. Em 3 de dezembro de 2021, foi relatado 263.563.622 casos confirmados de COVID-19 no mundo, e 5.232.562 mortes. Sendo, no Brasil, 22.105 .872 casos confirmados, e 614.964 mortes (World Health Organization, 2021b).

A transmissão do SARS-CoV-2 ocorre quando um indivíduo infectado tosse, espirra, fala ou é exposto a determinados procedimentos de saúde geradores de aerossóis (Lima et al., 2021). Dependendo da virulência, uma pessoa contaminada pode ser assintomática ou sintomática, ocasionando sintomas leves ou graves (Chen, 2020). Os sintomas agudos mais comuns de COVID-19 são febre, fadiga, diarreia e sintomas respiratórios, como tosse, dor de garganta e falta de ar (Larsen et al., 2020). Apesar da COVID-19 se manifestar principalmente como uma infecção do trato respiratório, os estudos atuais indicam que o vírus é capaz de atingir outros sistemas, como o cardiovascular, gastrointestinal, neurológico, hematopoiético, imunológico e renal (Qian et al., 2021), podendo complicar o quadro clínico dos indivíduos com COVID-19, dependendo da gravidade da infecção.

Desse modo, após a infecção pulmonar, o vírus pode entrar no sangue, acumular-se no rim e causar danos às células residentes, podendo causar complicações renais leves ou graves, como hematúria, proteinúria e até mesmo Insuficiência Renal Aguda (IRA). Tal situação acarreta em um risco significativamente maior para a piora clínica dos pacientes, podendo 
demandar terapia renal substitutiva (TRS), como hemodiálise, e até ocasionar o óbito (Casas-Aparicio et al., 2021; Qian et al., 2021; Hittesdorf et al., 2021; Chen, et at., 2020).

Diante disso, este estudo justifica-se pela necessidade de entender quais são as complicações do sistema renal provenientes da infecção pelo novo coronavírus que possam prejudicar a melhora clínica, ocasionar alguma sequela crônica renal, ou levar à morte, principalmente em pacientes que não apresentam nenhum histórico de doença renal. Compreender a gravidade dessa doença à nível renal é de suma importância para o enriquecimento do arcabouço teórico acerca da patogenia da COVID-19, podendo colaborar com medidas que contribuam para a redução dos danos ao sistema renal dos pacientes. Dessa forma, os objetivos desse estudo foram identificar complicações/sequelas renais decorrentes da infecção por SARSCoV-2 em pessoas com COVID-19; e descrever a característica de idade da população estudada.

\section{Metodologia}

Trata-se de um estudo do tipo "Scoping Review" ("Revisão de Escopo") embasada nas recomendações estabelecidas pelo Joanna Briggs Institute (JBI) no JBI Manual for Evidence Synthesis (2020) (Peters et al., 2020).

\subsection{Identificação da Pergunta Norteadora}

Visando a elaboração da estratégia de busca, primeiro foi realizada a construção da pergunta da pesquisa. Para isso, utilizou-se o acrômio PCC para Scoping Review, sendo: P - Population (População); C - Concept (Conceito); e C - Context (Contexto) (PETERS et al., 2020). Foram definidos: P - Pessoas com COVID-19; C - Complicações/sequelas renais decorrentes da infecção por SARS-CoV-2; e C - Pandemia da COVID-19. Com base nessas definições foi estabelecida a pergunta norteadora: "Quais as complicações/sequelas renais decorrentes da infecção por SARS-CoV-2 em pessoas com COVID-19?"

\subsection{Estratégia de Busca}

A busca dos estudos se configurou em três etapas: validação da estratégia de busca; realização da busca em todas as bases de dados e na literatura cinzenta; e realização da busca na lista de referências dos artigos selecionados para leitura na íntegra.

Na primeira etapa, realizou-se a validação da estratégia de busca, objetivando a verificação da precisão dos cruzamentos para obtenção dos estudos mais relevantes que respondessem à pergunta norteadora de forma mais condizente. Tal validação foi realizada em duas bases de dados previamente selecionadas pela autora, de acordo com a relevância de tais bases no âmbito científico, foram elas: Medical Literature Analysis and Retrieval System Online (MEDLINE) via PubMed, e Web Of Science. Ademais, foram testados vários cruzamentos dos operadores booleanos com os seguintes descritores e palavras-chaves: comorbidity, sequel, kidney diseases, acute kidney injury, coronavirus, SARS-CoV-2, COVID-19, complications, glomerular disease, nephropathy, kidney injury. A estratégia escolhida foi: “(comorbidity OR sequel OR complications) AND (kidney diseases OR glomerular disease OR acute kidney injury OR nephropathy) AND (coronavirus OR SARS-CoV-2 OR COVID-19)".

Após a validação e escolha de estratégia, executou-se a segunda etapa da pesquisa que foi a busca primária nas bases de dados online: MEDLINE via PubMed, Cumulative Index to Nursing and Allied Health Literature (CINAHL), Web Of Science, SCOPUS, Embase, Cochrane Library, Literatura Latino-Americana e do Caribe em Ciências da Saúde (LILACS), e Biblioteca Virtual em Saúde (BVS). Enquanto a busca na literatura cinzenta foi realizada nos seguintes sites online: ProQuest Dissertations and Theses, Grey Literature e Google Scholar. 
Após isso, foi executada a terceira e última etapa de identificação dos artigos. Esta foi executada a partir da leitura das referências dos artigos que foram selecionados para leitura na íntegra na segunda etapa.

A etapa de validação ocorreu do dia 02 de junho ao dia 16 de junho de 2021. Enquanto a coleta de dados da segunda e da terceira etapa foram realizadas do dia 09 de junho ao dia 29 de setembro de 2021.

Ressalta-se que para o gerenciamento e organização das referências, que foram coletadas durante todas as etapas da busca, foi utilizado o software online EndNote.

\subsection{Seleção dos Artigos}

Os estudos selecionados nas três etapas passaram por um processo rigoroso de triagem de títulos e resumos, até serem selecionados para leitura na íntegra. Os artigos que estavam em consonância com os critérios de elegibilidade estabelecidos foram selecionados para compor os resultados. Esse processo de triagem seguiu as recomendações da Statement for Reporting Systematic Reviews and Meta-Analyses of Studie - PRISMA (Galvão et al., 2015; Peters et al., 2020), conferindo consistência e veracidade ao presente estudo.

Teve-se como critérios de inclusão: pessoas que apresentaram complicações/sequelas renais em decorrência da COVID-19; artigos em português, inglês e espanhol, com abordagens metodológicas diversas, disponíveis na íntegra, online, publicados no período de 01 de janeiro de 2020 a 29 de setembro de 2021. Ressalva-se que não é característico de uma Scoping Review estabelecer um recorte temporal (Peters et al., 2020), no entanto, o uso de tal critério de inclusão neste estudo justificase pelo início dos relatos sobre a COVID-19, sendo o primeiro artigo científico publicado acerca deste tema datado de $01 / 01 / 2020$.

Adotou-se como critérios de exclusão: pessoas com diagnósticos prévios de patologias renais agudas e/ou crônicas; cartas ao editor; artigos de opinião; editoriais; e notas.

\subsection{Agrupamento, Resumo e Apresentação dos Resultados}

O primeiro agrupamento dos dados foi exposto em um fluxograma PRISMA, no qual continha os seguintes números: total de artigos identificados, de acordo com a fonte de obtenção dos dados; duplicatas; artigos que foram excluídos após a leitura dos títulos e resumos; artigos para leitura na íntegra; estudos que foram excluídos; e artigos para compor a revisão.

A partir disso, os dados dos estudos foram extraídos, resumidos e apresentados em uma tabela, que foi estruturada com todas as informações imprescindíveis que respondiam a pergunta norteadora, servindo para avaliação e verificação dos principais achados dos estudos selecionados. Essa tabela foi constituída com variáveis definidas previamente pela autora, sendo estas: título do artigo; autor(es) e ano; objetivos; metodologia; principais resultados; complicações/sequelas renais; e conclusões.

Diante das complicações/sequelas renais expostas na tabela, elaborou-se um gráfico que apresentava a porcentagem de citação dessas complicações nos artigos selecionados. Possibilitando maior nitidez e análise dos dados acerca dessa variável. O cálculo de porcentagem foi realizado por regra de três simples, em que a $1^{a}$ grandeza foi o número de artigos que a complicação renal foi citada e a $2^{\mathrm{a}}$ grandeza foi o valor em porcentagem, tendo 10 artigos como base máxima da $1^{\mathrm{a}}$ grandeza e $100 \%$ como base da $2^{\mathrm{a}}$ (IME/USP, 2021).

Além disso, elaborou-se um gráfico que apresentava a média de idade dos indivíduos que apresentaram alguma complicação renal em decorrência da infecção por SARS-CoV-2, de acordo com cada artigo selecionado que avaliou essa variável em seu estudo.

Ressalta-se que utilizou-se como parâmetro os critérios internacionais da KDIGO (Kidney Disease Improving Global Outcomes) (2012) para definição e classificação de IRA, de acordo com o valor de creatinina sérica e volume urinário. 


\section{Resultados}

Ao realizar a busca dos estudos, encontrou-se um total de 30.403 artigos, destes 9.102 foram excluídos por serem duplicatas, resultando em 21.301 artigos identificados. Desses, 21.228 artigos foram excluídos após a leitura dos títulos e resumos por não se adequarem ao tema proposto. Restou 73 artigos para leitura na íntegra, sendo que 63 foram excluídos por não responderem à questão norteadora e nem atenderem aos critérios de elegibilidade; restaram, como amostra final, 10 artigos para compor a revisão, como mostra o fluxograma PRISMA (Figura 1).

Figura 1. PRISMA flow diagram de coleta de artigos que compuseram os resultados.

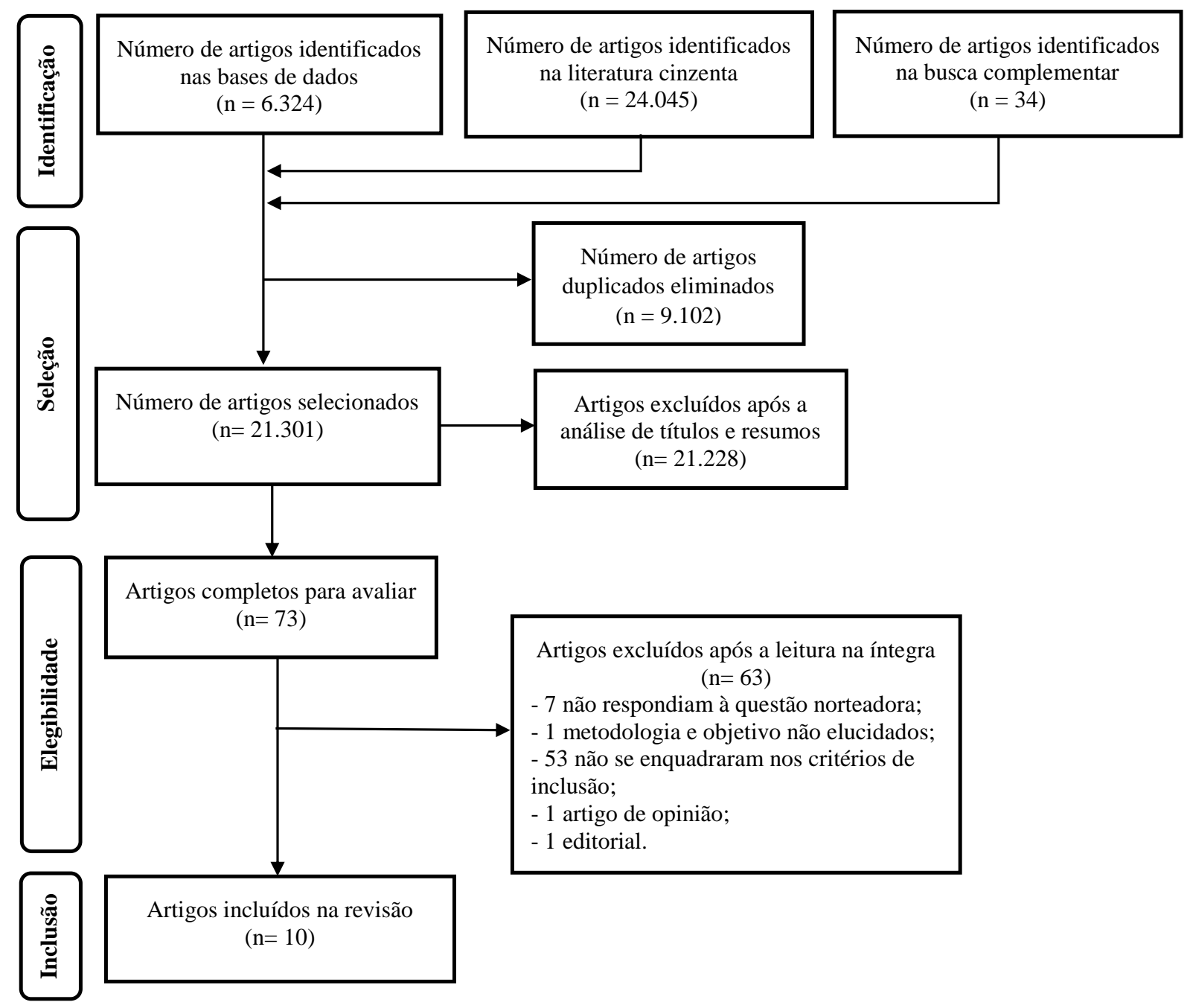

Fonte: Autores (2021).

Destaca-se que os 10 artigos selecionados estão escritos em língua inglesa, sendo 4 estudos de coorte retrospectivo, 5 revisões e 1 estudo de caso. A Tabela 1 sumariza os dados de cada estudo selecionado, sintetizando as informações de acordo com as seguintes variáveis: título do artigo; autores e ano de publicação; objetivos; metodologia do estudo; principais resultados; complicações/sequelas renais; e conclusões. 
Research, Society and Development, v. 11, n. 1, e40811125217, 2022

(CC BY 4.0) | ISSN 2525-3409 | DOI: http://dx.doi.org/10.33448/rsd-v11i1.25217

Tabela 1. Síntese geral dos artigos selecionados e apresentação dos principais achados sobre as complicações/ sequelas renais em pacientes com COVID-19, 2021.

\begin{tabular}{|c|c|c|c|c|c|c|}
\hline Título & Autor/Ano & Objetivos & Metodologia & Principais Resultados & $\begin{array}{l}\text { Complicações/ } \\
\text { sequelas renais }\end{array}$ & Conclusões \\
\hline $\begin{array}{c}\text { A1 } \\
\text { Acute kidney injury in } \\
\text { patients with severe } \\
\text { COVID-19 in Mexico }\end{array}$ & $\begin{array}{c}\text { Casas-Aparicio, } \\
\text { Gustavo A. et al./ } \\
2021\end{array}$ & 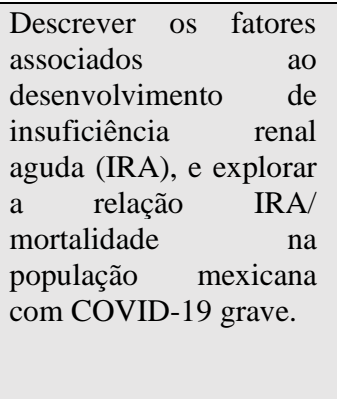 & $\begin{array}{c}\text { Estudo } \\
\text { quantitativo } \\
\text { retrospectivo }\end{array}$ & $\begin{array}{l}\text { O estudo apontou que } 58 \text { pacientes } \\
\text { desenvolveram IRA, destes, } 12 \text { tiveram IRA } \\
\text { estágio } 1(21,1 \%), 16 \text { tiveram IRA estágio } 2 \\
(28,1 \%) \text {, e } 29 \text { tiveram IRA estágio } 3(50,9 \%) \text {. } \\
\text { Além disso, } 41 \text { pacientes com IRA }(83,6 \%) \\
\text { necessitaram de ventilação mecânica } \\
\text { invasiva. Ademais, a mortalidade hospitalar } \\
\text { foi significativamente maior em pacientes } \\
\text { com IRA estágio } 3(79,3 \%) \text { e IRA estágio } 2 \\
(68,7 \%) \text { em comparação com aqueles com } \\
\text { IRA estágio } 1(25 \% ; p=0,01) \text {. }\end{array}$ & $\begin{array}{c}\text { Insuficiência Renal } \\
\text { Aguda (IRA) } \\
\text { estágio } 1,2 \text { e } 3\end{array}$ & $\begin{array}{l}\text { A IRA foi comum no grupo de pacientes } \\
\text { com pneumonia grave causada por } \\
\text { infecção por SARS-CoV-2. A } \\
\text { mortalidade foi mais frequente em } \\
\text { pacientes com IRA estágios } 2 \text { e } 3 \text {. }\end{array}$ \\
\hline $\begin{array}{c}\text { A2 } \\
\text { Mortality and renal } \\
\text { outcomes of patients } \\
\text { with severe COVID- } \\
19 \text { treated in a } \\
\text { provisional intensive } \\
\text { care unit }\end{array}$ & $\begin{array}{l}\text { Hittesdorf, Erin et } \\
\text { al./ } 2021\end{array}$ & $\begin{array}{l}\text { Avaliar a mortalidade e } \\
\text { os resultados renais de } \\
\text { médio prazo de } \\
\text { pacientes com COVID- } \\
19 \text { grave tratados em } \\
\text { uma Unidade de } \\
\text { Terapia Intensiva (UTI) } \\
\text { provisória. }\end{array}$ & $\begin{array}{l}\text { Estudo de } \\
\text { coorte } \\
\text { retrospectivo }\end{array}$ & $\begin{array}{l}24(20,9 \%) \text { dos } 116 \text { indivíduos } \\
\text { desenvolveram IRA estágio } 1,15(14,8 \%) \\
\text { IRA estágio } 2 \text { e } 37(30,4 \%) \text { IRA estágio } 3 \text {. } \\
\text { Pacientes com IRA estágio } 3 \text { apresentaram } \\
\text { maior probabilidade de necessitar de terapia } \\
\text { renal substitutiva (TRS) }(\mathrm{p}<0,001) \text { e morrer } \\
\text { durante a hospitalização }(\mathrm{p}<0,001) .45 \\
\text { pacientes posteriormente necessitaram de } \\
\text { TRS, quase todos TRS contínua, mas } 4 \\
\text { indivíduos foram submetidos a diálise } \\
\text { peritoneal transitória. Desses } 45 \text { pacientes, } 18 \\
\text { (40,0\%) morreram posteriormente. Os } 27 \\
\text { pacientes que sobreviveram necessitaram de } \\
\text { hemodiálise (HD) por } 15-20 \text { dias; } 22 \text { destes } \\
\text { (81,5\%) posteriormente necessitaram de HD } \\
\text { intermitente por } 12-14 \text { dias, e } 2 \text { necessitaram } \\
\text { de HD intermitente no momento da alta e aos } \\
90 \text { dias. }\end{array}$ & IRA estágio 1,2 e 3. & $\begin{array}{l}\text { Na avaliação a médio prazo ( } 90 \text { dias), } \\
\text { parece haver recuperação completa da } \\
\text { função renal na maioria dos pacientes. } \\
\text { Porém, o estudo aborda que é muito cedo } \\
\text { para comentar as sequelas renais em } \\
\text { longo prazo, sendo provável que apenas } \\
\text { poucos pacientes vão precisar de diálise, } \\
\text { e possíveis transplantes renais no futuro. }\end{array}$ \\
\hline $\begin{array}{l}\quad \mathbf{A 3} \\
\text { Extra-respiratory } \\
\text { manifestations of } \\
\text { COVID-19 }\end{array}$ & $\begin{array}{l}\text { Lai, Chih- Cheng } \\
\text { et al./2020 }\end{array}$ & $\begin{array}{lr}\text { Compreender } & \text { as } \\
\text { manifestações } & \text { extra- } \\
\text { respiratórias } & \text { de } \\
\text { COVID-19, } & \text { para } \\
\text { auxiliar } & \text { o entendimento } \\
\text { das } & \text { manifestações } \\
\text { clínicas. } & \end{array}$ & Revisão & $\begin{array}{l}\text { Com relação aos rins, a IRA foi uma das } \\
\text { manifestações extra-respiratórias mais } \\
\text { reportadas. Esta apresentou uma taxa de } \\
\text { prevalência de } 0,5 \% \text {, a qual sobe para } 2,9 \text { a } \\
23 \% \text { em casos mais graves de COVID- } 19 \text {. }\end{array}$ & IRA & $\begin{array}{l}\text { A prevalência de IRA é baixa, mas seu } \\
\text { risco pode aumentar com a gravidade de } \\
\text { COVID-19. }\end{array}$ \\
\hline $\begin{array}{c}\mathbf{A 4} \\
\text { Gastrointestinal and }\end{array}$ & $\begin{array}{l}\text { Maghool, } \\
\text { Fatemeh et al./ }\end{array}$ & $\begin{array}{l}\text { Resumir } \\
\text { complicações }\end{array}$ & Revisão & $\begin{array}{l}\text { Foi relatado que a IRA ocorre em } 6 \% \text { das } \\
\text { pessoas infectadas com SARS-CoV-2, }\end{array}$ & $\begin{array}{l}\text { IRA; deposição de } \\
\text { imunocomplexos }\end{array}$ & $\begin{array}{l}\text { Abordou que a tempestade de citocinas, } \\
\text { anticorpos anti-SARS-CoV-2, complexos }\end{array}$ \\
\hline
\end{tabular}


Research, Society and Development, v. 11, n. 1, e40811125217, 2022

(CC BY 4.0) | ISSN 2525-3409 | DOI: http://dx.doi.org/10.33448/rsd-v11i1.25217

renal complications in SARS-CoV-2-infected

patients: Role of

immune system

2021

gastrointestinais

renais em paciente

infectados com SARS

CoV-2 e o papel do

sistema imunológico $\mathrm{n}$

patogênese do vírus.

$\begin{array}{ccl}\begin{array}{c}\text { A5 } \\ \text { Renal changes and } \\ \text { acute kidney injury in } \\ \text { COVID-19: } \text { a } \\ \text { systematic review }\end{array} & \begin{array}{c}\text { Nogueira, Samuel } \\ \text { et al./2020 }\end{array} & \begin{array}{l}\text { Apresentar uma revisão } \\ \text { das alterações renais em } \\ \text { pacientes com COVID- }\end{array} \\ & & 19 . \\ & & \\ & & \\ \text { A6 } & \text { Paek, Jin Hyuk et } & \text { Identificar a incidência } \\ \text { de IRA em pacientes } \\ \text { com COVID-19 e } \\ \text { avaliar as características } \\ \text { clínicas da IRA e seu } \\ \text { impacto nos desfechos } \\ \text { dos pacientes. }\end{array}$

Revisão

Sistemática

(n)

podendo acontecer devido ao efeito citotrópico do vírus e à resposta inflamatória sistêmica induzida por citocinas. As respostas inflamatórias podem desencadear uma tempestade de citocinas, que induz hipóxia, choque e rabdomiólise e, portanto, causa lesão renal. Ademais, relatou que a desidratação nas pessoas com COVID-19 reduz a taxa de filtração glomerular e causa IRA. Enquanto a formação de complexos imunes vírus-anticorpo anti-SARS-CoV-2 se depositam nas células renais, e também podem contribuir para a lesão renal.

A IRA foi uma das manifestações mais citadas. Também houve mudanças significativas nos exames laboratoriais que indicaram lesão renal, como aumento da creatinina sérica e da ureia nitrogenada no sangue, proteinúria e hematúria. Estes achados foram mais prevalentes nos pacientes mais graves e, também, aos que chegaram a óbito em decorrência da COVID-19.A análise histopatológica do tecido renal de pacientes infectados com SARS-CoV-2 sugeriu que o vírus pode afetar diretamente os rins.

Estudo de

coorte

retrospectivo

Durante a internação, 4,0\% (28) dos 704 pacientes desenvolveram IRA. Entre esses, 15 $(53,6 \%)$ tinham IRA estágio $1,3(10,7 \%)$ IRA estágio 2 e $10(35,7 \%)$ IRA estágio 3. TRS foi aplicada a 8 pacientes e todos eles receberam TRS contínuas. 12 (43\%) se recuperaram, porém nenhum paciente se recuperou de IRA estágio 3. $13 \quad(46 \%)$ morreram. A incidência de mortalidade intrahospitalar em pacientes com IRA estágio 3 foi de $90 \%$, e 1 que sobreviveu ainda estava recebendo TRS contínuas. Ademais, os níveis de leucócitos, ureia nitrogenada no sangue, creatinina $\mathrm{e}$ proteína $\mathrm{C}$ reativa foram significativamente maiores no grupo com IRA. Além de apresentaram níveis mais baixos de hemoglobina, plaquetas, sódio e nas células renais; redução da taxa de ltração glomerular (TFG).

IRA; aumento da creatinina com consequente redução da TFG; proteinúria;

aumento da ureia

nitrogenada no

sangue; e hematúria.

IRA estágio 1,2 e 3 ; aumento da ureia nitrogenada no

sangue; aumento da creatinina com

consequente redução da TFG. munes e células imunes ativadas podem causar danos renais graves, como IRA, em pessoas com COVID-19.
Embora a COVID-19 afete principalmente os pulmões, também pode afetar os rins. Aumento da creatinina sérica e ureia, hematúria, proteinúria e IRA foram achados frequentes em pacientes com COVID-19 grave e foram relacionados a um aumento da taxa de mortalidade. 
Research, Society and Development, v. 11, n. 1, e40811125217, 2022

(CC BY 4.0) | ISSN 2525-3409 | DOI: http://dx.doi.org/10.33448/rsd-v11i1.25217

TFG.

The incidence, risk factors and prognosis of acute kidney injur in severe and critically ill patients with COVID-19 in mainland China: a retrospective study

\section{A8}

COVID-19 and acute kidney injury; a case report
Ghobadi, Hassan et al./ 2020 ang, Ling et al./2020

Avaliar a incidência, os fatores de risco e o prognóstico de IRA em pacientes graves criticamente enfermo com Covid-19.

Apresentar a evolução clínica associada à IRA em um caso confirmado de COVID-19.
Estudo

quantitativo

retrospectivo

de 210 pacientes, $92 \quad(43,8 \%)$ desenvolveram IRA durante a internação. Destes, $13(14,1 \%), 15(16,3 \%)$ e $64(69,6 \%)$ foram classificados como IRA estágio 1, 2 e 3 , respectivamente. $54(58,7 \%)$ receberam TRS contínua. A recuperação renal durante a internação foi identificada em 16 pacientes com IRA $(17,4 \%)$, que apresentaram tempo significativamente menor da admissão ao diagnóstico de IRA. Ademais, $93(44.3 \%)$

Estudo de caso $\begin{aligned} & \text { faleceram em } 28 \text { dias de admissão na UTI. } \\ & \text { Neste clínico, a IRA foi identificada }\end{aligned}$ durante a permanência do paciente na UTI. Os resultados de testes laboratoriais apresentaram valores médios de creatinina e ureia nitrogenada no sangue de $3,1 \mathrm{mg} / \mathrm{dL}$ (valor normal: $0,6-1,2 \mathrm{mg} / \mathrm{dL}$ ) e $145 \mathrm{mg} / \mathrm{dL}$ (valor normal: $15-45 \quad \mathrm{mg} / \mathrm{dL}$ ), respectivamente, confirmando o diagnóstico de IRA.

O envolvimento renal se manifesta principalmente como proteinúria e IRA. O dano renal induzido por SARS-CoV-2 deve ser multifatorial; diretamente, pode infectar os podócitos renais e células tubulares proximais e, com base na via da enzima conversora de angiotensina 2 (ACE2), pode levar à necrose tubular aguda, vazamento de proteína na cápsula de Bowman, colapso da glomerulopatia e comprometimento mitocondrial. A desregulação das respostas imunológicas induzida por SARS-CoV-2, incluindo tempestade de citocinas, síndrome de ativação de macrófagos e linfopenia, podem ser outras causas da IRA. Interações de órgãos, disfunção endotelial, hipercoagulabilidade, rabdomiólise e sepse
IRA estágio $1,2 \mathrm{e}$

3 ; aumento da

creatinina sérica.

IRA; aumento da creatinina sérica; aumento da ureia nitrogenada no

sangue.

\section{IRA, proteinúria e hematúria}

fisiopatologia da lesão renal.
Entre os pacientes com COVID-19, a incidência de IRA foi alta. Os achados dos fatores de risco para o desenvolvimento de IRA (idade, sepse, droga nefrotóxica, ventilação mecânica invasiva e níveis basais elevados de creatinina sérica) e fatores associados à recuperação da função renal podem informar o manejo clínico de pacientes com doença crítica de COVID-19.

$\mathrm{O}$ estudo apontou que a IRA foi identificada durante o curso do paciente na UTI, sendo condizente com estudos anteriores que mostraram a presença de IRA em pacientes hospitalizados com COVID-19. Salientou também que mesmo pequenas variações agudas na função renal podem resultar em consequências terríveis de curto e longo prazo, incluindo doença renal crônica (DRC), doença renal em estágio terminal e morte.

A fisiopatologia da LRA pode estar associada a mecanismos específicos de COVID (entrada viral direta, ativação RAS desequilibrada, citocinas próinflamatórias provocadas pela infecção viral e estado trombótico) e mecanismos inespecíficos (insuficiência cardíaca direita, hipovolemia, sepse nosocomial, nefrotóxica medicamentos, PEEP elevada em casos que requerem ventilação mecânica e alterações hemodinâmicas). A disfunção renal ocorre em casos com Covid-19 dentro de 3 semanas após o início dos sintomas; e as complicações renais estão relacionadas com uma mortalidade mais elevada. 
Research, Society and Development, v. 11, n. 1, e40811125217, 2022

(CC BY 4.0) | ISSN 2525-3409 | DOI: http://dx.doi.org/10.33448/rsd-v11i1.25217

\begin{tabular}{|c|c|c|c|c|c|c|}
\hline & & & & $\begin{array}{l}\text { são outros mecanismos potenciais de IRA. } \\
\text { Além disso, a entrega mais baixa de oxigênio } \\
\text { aos rins pode causar lesão isquêmica. }\end{array}$ & & \\
\hline $\begin{array}{c}\mathbf{A 1 0} \\
\text { Acute kidney injury in } \\
\text { COVID-19; a review } \\
\text { on current knowledge }\end{array}$ & $\begin{array}{l}\text { Aleebrahim- } \\
\text { Dehkordi, Elahe } \\
\text { et al./ } 2020\end{array}$ & $\begin{array}{l}\text { Investigar o efeito do } \\
\text { novo coronavírus } \\
\text { (SARS-CoV-2) no rim e } \\
\text { seu papel no } \\
\text { desenvolvimento de } \\
\text { insuficiência renal. }\end{array}$ & Revisão & $\begin{array}{l}\text { O artigo relatou que alguns artigos afirmaram } \\
\text { que o SARS-CoV-2 se acumulava nos } \\
\text { túbulos renais, induzindo IRA. Ademais, os } \\
\text { estudos com pacientes hospitalizados com } \\
\text { COVID-19 expuseram que essas pessoas } \\
\text { desenvolveram albuminúria maciça no } \\
\text { primeiro dia de internação, proteinúria e } \\
\text { hematúria durante sua permanência no } \\
\text { hospital. Também houve prevalência nas } \\
\text { taxas de ureia sanguínea }(14,1 \%) \text { e creatinina } \\
\text { sérica }(15,5 \%) \text {. }\end{array}$ & $\begin{array}{c}\text { IRA; proteinúria; } \\
\text { hematúria; aumento } \\
\text { da creatinina sérica; } \\
\text { aumento de ureia no } \\
\text { sangue. }\end{array}$ & $\begin{array}{l}\text { O novo coronavírus pode causar } \\
\text { comprometimento renal, especificamente } \\
\text { IRA. Havendo vários achados clínicos e } \\
\text { laboratoriais em pacientes com COVID- } \\
19 \text { e IRA, como hematúria, proteinúria e } \\
\text { aumento das taxas de creatinina sérica e } \\
\text { ureia sanguínea. }\end{array}$ \\
\hline
\end{tabular}

Fonte: Autores (2021). 
De acordo com os estudos da Tabela 1, as complicações/sequelas renais decorrentes da infecção por SARS-CoV-2 em pessoas com COVID-19 são: deposição de imunocomplexos nas células renais, proteinúria, hematúria, aumento da creatinina sérica, aumento da ureia nitrogenada no sangue, diminuição da TFG, e IRA estágio 1, 2 e 3. Segundo o Gráfico $1,100 \%(\mathrm{n}=10)$ dos artigos relataram que IRA é uma complicação renal, seguida de 50\% ( $\mathrm{n}=5)$ que inferiram sobre o aumento da creatinina sérica, e 40\% $(\mathrm{n}=4)$ que destacaram o aumento da ureia nitrogenada no sangue. Ademais, 30\% ( $\mathrm{n}=3$ ) dos estudos apontaram proteinúria, hematúria e redução da TFG como alteração renal, de modo conjunto ou isolado; e 10\% $(\mathrm{n}=1)$ citou a deposição de imunocomplexos nas células renais.

Gráfico 1. Complicações/sequelas renais de acordo com seu número de citações entre os artigos selecionados. $100 \%$

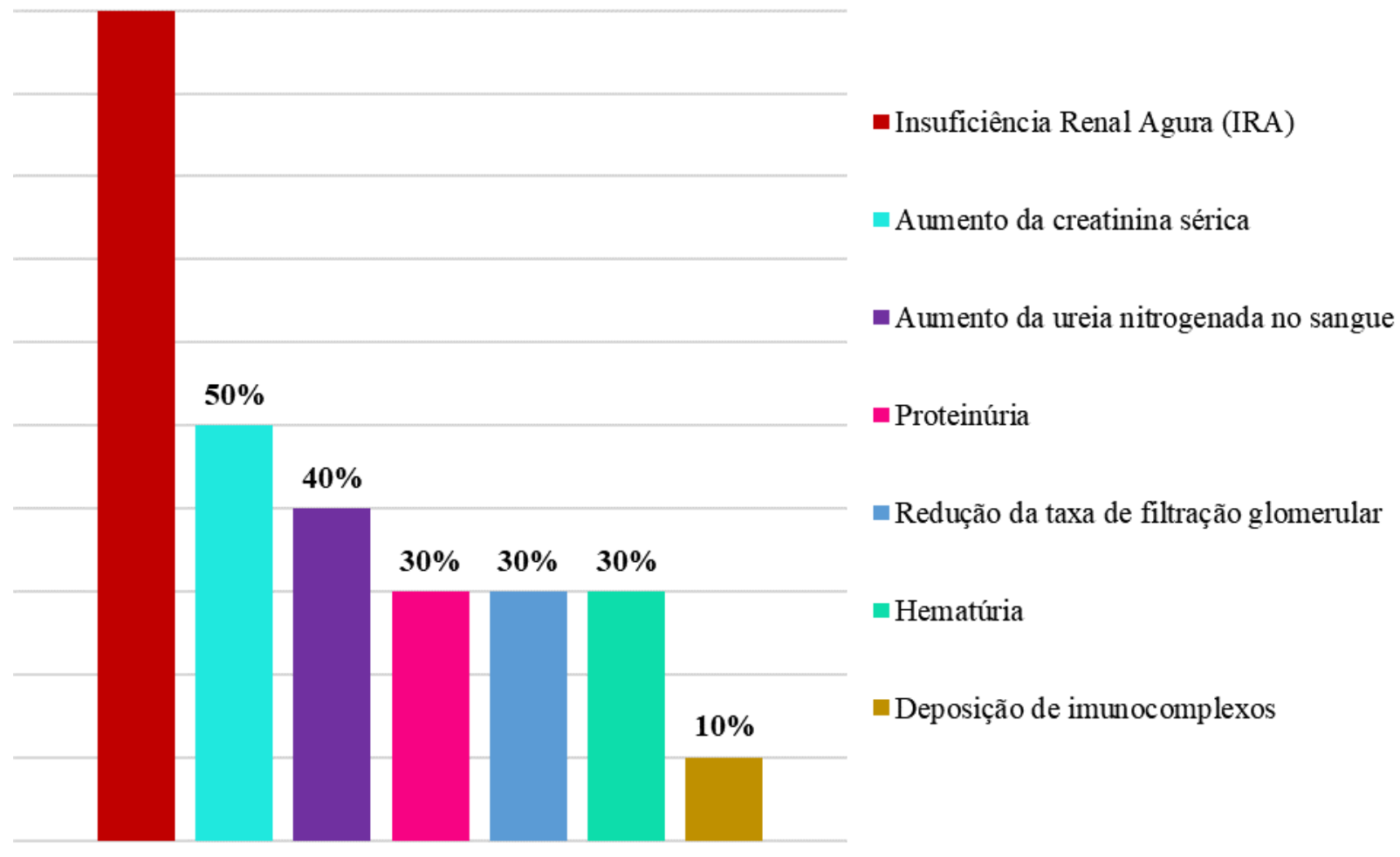

Fonte: Autores (2021).

Referente à idade dos indivíduos que apresentaram alguma complicação renal em decorrência da infecção por SARS-CoV-2, o Gráfico 2 expôs que a média de idade foi, segundo o artigo A1, de 53 anos, enquanto no artigo A2, a média foi de 69 anos. Já os estudos A6 e A7, identificaram uma média de 65 anos. Além disso, o artigo A8 informou um valor médio de 32 anos de idade. No entanto, os estudos A3, A4, A5, A9 e A10 não avaliaram a variável faixa etária, assim, não foram incluídos no Gráfico 2.

\section{Discussão}

Os resultados demonstraram relevantes complicações/sequelas renais decorrentes da infecção por SARS-CoV-2 em pessoas com COVID-19, tais como deposição de imunocomplexos nas células renais, proteinúria, hematúria, aumento da ureia nitrogenada no sangue, aumento da creatinina sérica e redução da TFG. Essas complicações inflamatórias no tecido renal podem ocasionar lesões renais graves como IRA, que é a consequência renal mais apontada por todos estudos presentes nos resultados. 
Referente à idade, os artigos A1, A2, A6 e A7 informaram que indivíduos entre 52-69 anos são os que mais foram acometidos por complicações renais em decorrência da infecção pelo SARS-CoV-2. Tal fato é ratificado por relatos científicos de que o novo coronavírus tem maior probabilidade de infectar pacientes com funções imunológicas debilitadas, como pacientes idosos. Dessa forma, a idade avançada foi identificada como um fator de risco para IRA em pacientes hospitalizados com COVID-19, sendo a taxa de mortalidade intra-hospitalar maior nessa população (Cheng et al., 2020; Hirsch et al., 2020; Paek, et al., 2020). Entretanto, o artigo A8 informou uma média de idade de 32 anos. Tal informação provavelmente não foi condizente com os estudos supracitados por tratar-se de um estudo de caso clínico com apenas um paciente $(\mathrm{n}=1)$.

$\mathrm{O}$ artigo A4 relatou que os anticorpos anti-SARS-CoV-2 secretados pelo organismo ligam-se aos antígenos virais e levam à formação de complexos imunes vírus-anticorpo no tecido renal. Essa deposição de imunocomplexos, agregada às respostas imunológicas humorais que ocorrem por meio de mecanismos efetores imunes específicos, induzidos por vírus (linfócitos T ou anticorpos específicos), podem causar danos severos aos rins (Maghool et al., 2021; Cheng et al., 2020).

Referente à proteinúria e a hematúria, os artigos A5, A9 e A10 abordaram que elas foram achados urinários anormais recorrentes em pacientes com COVID-19 grave, sendo indicativo de que essa patologia afeta os rins. Dessa forma, segundo esses estudos, o exame de urina com tais resultados configura-se como um dos testes de diagnóstico indicativo de lesão renal decorrente da infecção por SARS-CoV-2.

Segundo a literatura científica atual, a proteinúria provavelmente resulta da replicação do SARS-CoV-2 nos podócitos dos túbulos renais, da infecção epitelial desses túbulos e de outras lesões teciduais (Cheng et al., 2020; Su et al., 2020). Chen, T. et al. (2020) expôs em sua pesquisa que a proteinúria foi encontrada em $60,24 \%$ dos pacientes com COVID-19 que realizaram rotineiramente o exame de urina. Ademais, outro estudo com 59 pacientes, realizado na China, inferiu que $34 \%$ dos pacientes desenvolveram albuminúria maciça no primeiro dia de admissão hospitalar e $63 \%$ desenvolveram proteinúria durante sua permanência no hospital (Li et al., 2020).

Além disso, eventos clínicos como hematúria e proteinúria foram observados em aproximadamente $40 \%$ dos pacientes com COVID-19 (Rabb, 2020). Em concordância, Cheng et al. (2020) relatou que 44\% das pessoas hospitalizados com COVID-19 tinham proteinúria e hematúria, e 26,7\% tinham hematúria na admissão. Assim como outra pesquisa expôs que 50,6\% dos pacientes com COVID-19 apresentaram hematúria microscópica (Chen, et al., 2020).

Assim como as consequências renais anteriores, os artigos A5, A6, A8 e A10 afirmaram que o aumento da ureia nitrogenada no sangue é uma alteração orgânica que também caracteriza alteração na função dos rins em decorrência da ação infecciosa do SARS-CoV-2 nesses órgãos. Sabe-se que o sistema renina-angiotensina-aldosterona aumenta a absorção de água e sódio nos túbulos renais, causando reabsorção passiva da ureia nitrogenada. Em paralelo, o novo coronavírus pode afetar a função renal ao entrar nas células renais de uma forma direta dependente de ECA2 e ativar o SRAA. Consequentemente, os efeitos sistêmicos da ativação desse sistema causam vasoconstrição renal e, por conseguinte, a filtração glomerular diminui, e a excreção de creatinina e ureia nitrogenada são reduzidas (Ok et al., 2021; Murata et al., 2017).

Ademais, o aumento da ureia nitrogenada pode estar associado à gravidade da lesão renal, podendo ser um indicativo de predisposição ao desenvolvimento de IRA no indivíduo com COVID-19. Em um estudo realizado na Coreia do Sul, que avaliou 704 pacientes com COVID-19, foi identificado que os níveis de ureia nitrogenada no sangue foi significativamente maior no grupo de pessoa com IRA do que no grupo de pacientes que não apresentaram IRA (Paek et al., 2020). Tal aumento também pode estar relacionado com a taxa de mortalidade desses pacientes. Um outro estudo com 701 pacientes corrobora com esta suposição, pois inferiu em seus resultados que a ureia nitrogenada no sangue foi elevada em $27 \%$ no geral e em dois terços das pessoas que faleceram (Cheng et al. 2020). 
O aumento da creatinina sérica, que foi abordado pelos artigos A5, A6, A7, A8 e A10, segue o mesmo preceito fisiológico da ativação do SRAA pelo SARS-CoV-2, conforme exposto anteriormente. No entanto, diferente da suposição da relação entre aumento de ureia nitrogenada e IRA, o aumento da creatinina sérica em relação ao valor basal é, cientificamente comprovado, um dos critérios clínicos de IRA (KDIGO, 2012; Khwaja, 2012). Antes da pandemia de COVID-19, outros estudos já apontavam que os valores elevados de creatinina sérica estavam associados ao desenvolvimento de IRA em pessoas adultas (Panitchote et al., 2019).

Atualmente, no estudo realizado por Sang et al. (2020), com 210 pacientes com COVID-19, 92 pessoas desenvolveram IRA e apresentaram altos níveis de creatinina sérica, com média de $67,1 \mu \mathrm{mol} / \mathrm{L}$. Assim como um estudo de caso clínico, em que a pessoa com COVID-19 apresentava um valor médio de creatinina de 3,1 mg/dL (Ghobadi et al., 2020). Desse modo, as pesquisas apontaram que o aumento da creatinina sérica possivelmente já é um indicativo esperado de injúria renal em pacientes com infecção severa por SARS-CoV-2, servindo como um alerta precoce para amenizar/conter a severidade da patologia renal (Nogueira et al., 2020).

No contexto do aumento das excretas nitrogenadas no sangue dos indivíduos com COVID-19, compreendeu-se que isto ocorreu devido a diminuição da capacidade de filtração dos rins, como exposto anteriormente. Em decorrência disso, houve a diminuição da taxa de filtração glomerular dessas pessoas, como foi notoriamente identificado pelos artigos A4, A5 e A6. Estudos apontam que pessoas que apresentaram uma taxa normal de creatinina no teste durante admissão hospitalar, tiveram um aumento no segundo teste, seguido por uma diminuição da TFG (Yang, R. et al., 2020; Nogueira et al., 2020; Paek, et al., 2020).

Yang, F. et al. (2020) ratifica tal constatação, em seu estudo realizado com 97 pacientes hospitalizados, ao afirmar que houve um aumento nos níveis de creatinina, acompanhado por uma diminuição da TFG, com níveis médios de 18,0 $\mathrm{mL} / \mathrm{min}$. Nesse mesmo sentido, Nogueira et al. (2020) inferiu que a taxa de filtração glomerular estimada (TFGe) média dos pacientes com creatinina sérica elevada era de $48 \mathrm{~mL} / \mathrm{min} / 1,73 \mathrm{~m}^{2}$, afirmando, assim como os demais autores dos artigos A4, A5 e A6, que isso corroborava para o desenvolvimento de insuficiência renal.

De modo unânime, os 10 artigos selecionados expuseram que a IRA é uma complicação decorrente da desregulação da função renal causada pela ação dos SARS-CoV-2, havendo a diminuição da filtração glomerular e consequente aumento das excretas nitrogenadas, findando na redução da TFG, causando injúria aguda nos rins. Ressalta-se que muitos estudos abordam que o risco do desenvolvimento de IRA aumenta de acordo com o grau de severidade da COVID-19 (Qian et al., 2021; Casas-Aparicio et al., 2021; Hittesdorf et al., 2021; Lai et al., 2020; Chong \& Saha, 2020).

Segundo uma pesquisa realizada no México, dos 224 pacientes com COVID-19 admitidos no hospital, 60,7\% desenvolveram IRA no hospital e, entre eles, 29\% tiveram IRA estágio 3 (Ramirez-Sandoval et al., 2020). Semelhante a isso, outro estudo feito nos Estados Unidos da América (EUA) inferiu que, dos 5449 pacientes avaliados, 36,6\% (1993) desenvolveram IRA durante sua hospitalização, sendo IRA estágio 1 em 46,5\%, o estágio 2 em 22,4\%, e o estágio 3 em $31,1 \%$ (Hirsch et al., 2020). Ademais, Diao et al. (2021) demonstrou em sua pesquisa que 27,06\%, dos 85 pacientes com COVID-19, desenvolveram IRA.

Além disso, a incidência de IRA nessas pessoas tem potencial para agravar a situação clínica delas, a depender, principalmente, do estágio da insuficiência. Dessa forma, a ocorrência de IRA pode: demandar terapia renal substitutiva, como hemodiálise ou diálise peritoneal; causar cronificação da insuficiência; ou acarretar ao óbito. No entanto, apesar da TRS, a probabilidade de não recuperação dos pacientes com IRA estágio 3 é superior à de cura. Geralmente, devido à gravidade da injúria renal desse estágio, os indivíduos são mais propícios ao falecimento. Casas-Aparicio et al. (2021) corrobora com tal proposição ao relatar que a mortalidade hospitalar é particularmente elevada em pacientes com IRA estágios 2 e 3. 
Também, em um estudo realizado na China, com 210 pacientes com COVID-19, apenas 17,4\% dos pacientes com IRA recuperaram a função renal durante a hospitalização (Sang et al., 2020). Enquanto Hittesdorf et al. (2021) afirmou que pacientes com IRA em estágio 3 eram mais propensos a necessitar de TRS. Em seu estudo, 45, de 116 pessoas hospitalizadas, necessitaram de TRS, e 40\% delas entraram em óbito. De modo confluente, Paek et al. (2020) relatou em sua pesquisa que $28,5 \%$, de 28 pacientes com IRA, necessitaram de TRS. Entretanto, nenhum indivíduo em TRS no estágio 3 se recuperou, e $46 \%$, do total, faleceram, sendo de $90 \%$ a incidência de mortalidade hospitalar em pacientes com IRA estágio 3. A mortalidade hospitalar foi particularmente elevada em pacientes com IRA estágios 2 e 3.

Apesar disso, ainda é escasso a quantidade de estudos que abordam a possibilidade de agravamento do quadro de IRA para Doença Renal Crônica (DRC). Dentre os estudos presentes nos resultados, apenas o artigo A8 debateu sobre tal possibilidade, dispondo que pequenas variações agudas na função renal podem resultar em consequências terríveis de curto e longo prazo, incluindo doença renal crônica (Ghobadi et al., 2020). Isto provavelmente está relacionado à severidade/letalidade da injúria renal causada pelo SARS-CoV-2, como discorrido anteriormente, não havendo margem temporal para a cronificação da doença.

\section{Considerações Finais}

Diante das análises feitas nesse estudo, identificou-se que as complicações/sequelas renais, decorrentes da infecção por SARS-CoV-2 em pessoas com COVID-19, podem ser a deposição de imunocomplexos nas células renais, proteinúria, hematúria, aumento da creatinina sérica e da ureia nitrogenada no sangue, diminuição da TFG, e IRA estágio 1, 2 ou 3. Essas complicações ocorrem com mais frequência em indivíduos com idade $\geq 52$ anos, e estão relacionadas à afinidade histofisiológica do SARS-CoV-2 com os rins, favorecendo o processo infecioso desses órgãos. Os estudos abordaram que esse processo infeccioso pode iniciar com uma leve proteinúria e hematúria, que geralmente é identificada nos exames de admissão hospitalar, e evoluir para uma injúria renal aguda causada pela diminuição da capacidade de filtração glomerular, que favorece a retenção de algumas escórias nitrogenadas, causando o aumento dos níveis de creatinina e de ureia.

Aponta-se também a agilidade do agravamento do quadro clínico e o poder de letalidade que essas consequências renais podem ocasionar nos pacientes, principalmente naqueles diagnosticados com IRA estágio 3. Entretanto, não há evidências científicas atuais suficientes que possibilitem a dedução de que esse agravamento do quadro e posterior óbito esteja intrinsicamente associado à infecção do SARS-CoV-2 nos rins ou à fisiopatologia geral da doença. Tal fato assinala a importância de novos estudos que consigam abordar essa diferenciação. Por outro lado, pôde-se inferir, por enquanto, que a cronificação da insuficiência renal é uma situação atípica nesse processo patológico, visto que a maioria dos estudos apontaram que paciente ou evolui para cura ou vai à óbito.

Ressalta-se, como limitação deste estudo, a pouca quantidade de referencial teórico disponível na literatura atual acerca do tema, devido tanto ao fato da pandemia estar associada a uma nova cepa de coronavírus, quanto ao fato de poucos estudos primários que visem analisar especificamente o acometimento renal em indivíduos com COVID-19 que não apresentam nenhuma lesão nos rins. Dessa forma, destaca-se a necessidade e importância de mais estudos primários com esse tema, podendo, assim, colaborar ainda mais com as evidências científicas e, sobretudo, com a humanidade.

\section{Referências}

Ahmadian, E. et al (2021). Covid-19 and kidney injury: Pathophysiology and molecular mechanisms. Rev. Med. Virol., 31 :e2176. https://doi.org/10.1002/rmv.2176.

Aleebrahim-Dehkordi, E. et al. (2020). Acute kidney injury in COVID-19; a review on current knowledge. J. Nephropathol., 9(4):e31. https://doi.org/10.34172/jnp.2020.31. 
Casas-Aparicio, G., et al. (2021). Acute kidney injury in patients with severe COVID-19 in Mexico. PLoS ONE, 16(2): e0246595. 2021. https://doi.org/10.1371/journal.pone.0246595.

Chen, N., et al. (2020). Epidemiological and clinical characteristics of 99 cases of 2019 novel coronavirus pneumonia in Wuhan, China: a descriptive study. Lancet, 395: 507-13. https://doi.org/10.1016/S0140-6736(20)30211-7.

Chen, T., et al. (2020). Clinical characteristics of 113 deceased patients with coronavirus disease 2019: retrospective study. BMJ, 368:m1091. https://doi.org/10.1136/bmj.m1091.

Cheng, Y., et al. (2020). Kidney disease is associated with in-hospital death of patients with COVID-19. Kidney International. https://doi.org/10.1016/j.kint.2020.03.005.

Chong, W. H. \& Saha, B. (2021). Relationship Between Severe Acute Respiratory Syndrome Coronavirus 2 (SARS-CoV-2) and the Etiology of Acute Kidney Injury (AKI). Am. J. Med. Sci., 361(3):287-296. 2021. https://doi.org/10.1016/j.amjms.2020.10.025.

Diao, B., et al. (2021). Human kidney is a target for novel severe acute respiratory syndrome coronavirus 2 infection. Nature Communications, 12:2506. https://doi.org/10.1038/s41467-021-22781-1.

Galvão, T. F.; Pansani, T. S. A. \& Harrad, D. (2015). Principais itens para relatar Revisões sistemáticas e Meta-análises: A recomendação PRISMA*. Epidemiol. Serv. Saúde, 24(2): abr-jun. https://doi.org/10.5123/S1679-49742015000200017.

Ghobadi, H., et al. (2020). COVID-19 and acute kidney injury; a case report. J. Renal Inj Prev., 9(3): e26. https://doi.org/10.34172/jrip.2020.26.

Hirsch, J. S. et al. (2020). Acute kidney injury in patients hospitalized with COVID-19. Kidney International. https://doi.org/10.1016/j.kint.2020.05.006.

Hittesdorf, E., et al. (2021). Mortality and renal outcomes of patients with severe COVID-19 treated in a provisional intensive care unit. Journal of Critical Care. https://doi.org/10.1016/j.jcrc.2020.12.012.

IME/USP (2021). Instituto de Matemática e Estatística da Universidade de São Paulo. Matemática Financeira. https://www.ime.usp.br/ salles/fatec/material_antigo/financeira/Matematica\%20Financeira2.pdf.

KDIGO (2012). Kidney Disease Improving Global Outcomes. KDIGO Clinical Practice Guideline for Acute Kidney Injury. Definition and classification of AKI. Kidney International Supplements. Vol. 02.

Khwaja, A. (2012). KDIGO Clinical Practice Guidelines for Acute Kidney Injury. Nephron Clin Pract., 120:c179-c184. 2012. https://doi.org/10.1159/000339789.

Lai, C-C. et al. (2020). Extra-respiratory manifestations of COVID-19. International Journal of Antimicrobial Agents. https://doi.org/10.1016/j.ijantimicag.2020.106024.

Larsen, J. R. et al. (2020). Modeling the Onset of Symptoms of COVID-19. Frontiers in Public Health, vol. 08. https://doi.org/10.3389/fpubh.2020.00473.

Li, Z. et al. (2020). Caution on Kidney Dysfunctions of COVID-19 Patients. Medrxiv. https://doi.org/10.1101/2020.02.08.20021212.

Lima, A. A., et al. (2021). Characteristics of SARS-cov-2 aerosol dispersion in indoor air: scoping review. Research, Society and Development, v. 10, n. 4, e44310414300. http://dx.doi.org/10.33448/rsd-v10i4.14300.

Maghool, F. et al. (2021). Gastrointestinal and renal complications in SARS-cov-2-infected patients: Role of immune system. Scand. J. Immunol. https://doi.org/10.1111/sji.12999.

Murata, A., et al. (2018). Relationship between blood urea nitrogen-to-creatinine ratio at hospital admission and long-term mortality in patients with acute decompensated heart failure. Heart and Vessels, 33:877-885. 2018. https://doi.org/10.1007/s00380-018-1135-3.

Nogueira, S. Á. R., et al. (2020). Renal changes and acute kidney injury in covid-19: a systematic review. VER. ASSOC. MED. BRAS. http://dx.doi.org/10.1590/1806-9282.66.S2.112.

Organização Pan-Americana de Saúde (2020). Histórico da pandemia de COVID-19. https://www.paho.org/pt/covid19/historico-da-pandemia-covid-19.

Ok, F. et al. (2021). Predictive values of blood urea nitrogen/creatinine ratio and other routine blood parameters on disease severity and survival of COVID-19 patients. J. Med. Virol., 93:786-793. https://doi.org/10.1002/jmv.26300.

Paek, J. H., et al. (2020). Severe acute kidney injury in COVID-19 patients is associated with in-hospital mortality. Plos ONE, 15(12): e0243528. https://doi.org/10.1371/journal.pone.0243528.

Panitchote, A., et al. (2019). Factors associated with acute kidney injury in acute respiratory distress syndrome. Ann. Intensive Care. https://doi.org/10.1186/s13613-019-0552-5.

Peters, M. D. J. et al. (202). Chapter 11: Scoping Reviews (2020 version). JBI Manual for Evidence Synthesis.

Qian, J-Y et al. (2021). Pathogenesis of Acute Kidney Injury in Coronavirus Disease 2019. Frontiers in Public Health, 12. https://doi.org/10.3389/fphys.2021.586589.

Rabb, H. (2020). Kidney diseases in the time of COVID-19: major challenges to patient care. J. Clin Invest., 130(6):2749-2751. https://doi.org/10.1172/JCI138871. 
Research, Society and Development, v. 11, n. 1, e40811125217, 2022

(CC BY 4.0) | ISSN 2525-3409 | DOI: http://dx.doi.org/10.33448/rsd-v11i1.25217

Ramirez-Sandoval, J. C. et al. (2021). Prolonged Intermittent Renal Replacement Therapy for Acute Kidney Injury in COVID-19 Patients with Acute Respiratory Distress Syndrome. Blood Purif., 50:355-363. 2021. https://doi.org/10.1159/000510996.

Sang, L., et al. (2020). The incidence, risk factors and prognosis of acute kidney injury in severe and critically ill patients with COVID-19 in mainland China: a retrospective study. BMC Pulmonary Medicine. https://doi.org/10.1186/s12890-020-01305-5.

Su, H., et al. (2020). Renal histopathological analysis of 26 postmortem findings of patients with COVID-19 in China. Kidney International. https://doi.org/10.1016/j.kint.2020.04.003.

World Health Organization (2021a). Coronavirus disease (COVID-19). https://www.who.int/health-topics/coronavirus\#tab=tab_3.

World Health Organization (2021b). WHO Coronavirus (COVID-19) Dashboard. https://covid19.who.int.

Yang, F., et al. (2020). Analysis of 92 deceased patients with COVID-19. J. Med. Virol., 92:2511-2515. https://doi.org/10.1002/jmv.25891.

Yang, R., et al. (2020). The role of essential organ-based comorbidities in the prognosis of COVID-19 infection patients. EXPERT REVIEW OF RESPIRATORY MEDICINE, 14(8), 835-838. https://doi.org/10.1080/17476348.2020.1761791. 